\title{
Stigmata of Congenital Syphilis on a High Status Juvenile at Yuguë, Oaxaca, Mexico
}

\author{
Arion T. Mayes ${ }^{1}$, Anamay Melmed ${ }^{1}$, and Sarah Barber ${ }^{2}$ \\ ${ }^{1}$ Department of Anthropology, San Diego State University, CA 92182 \\ ${ }^{2}$ Department of Anthropology, University of Central Florida, FL 32816
}

ABSTRACT Presented here is a case study from
Mesoamerica whose dentition resembles the dental
stigmata of others who have been described as
having congenital syphilis. Found with a green stone
bracelet, this child was likely a high-status member of
a pre-Colombian population from the Pacific Coast of
Oaxaca, Mexico (late Terminal Formative Period, 150
BCE - CE 250). While taphonomic changes precluded

There are four treponemal syndromes, as identified by their subspecies of treponematosis, the expression of which differs in relation to environment and, possibly, host responses. Three of these syndromes can affect the skeleton, namely yaws (Treponematosis pallidum subsp. pertenue), bejal or endemic syphilis (T.p. subsp. Endemicum), and venereal syphilis (T.p. subsp. pallidum.), which includes congenital syphilis. In the living, a clinical diagnosis as to which treponemal syndrome a patient may have can be difficult (Landrum et al., 2005). In cases where symptoms of one syndrome may mirror the other, DNA analysis aids in differential diagnosis (Centurion-Lara et al., 1998; Kolman et al., 1999; Landrum et al., 2005). With archaeological specimens, a positive identification using genetic testing depends on the amount of available, viable DNA. In circumstances where taphonomic change has affected DNA viability, one must rely on skeletal changes. Patterns of affected bones characteristic of syphilis do aid in diagnosis, but not every case follows the same pattern, thus complicating its identification in the archaeological record (Ortner, 2003). The same has been true of congenital syphilis with one significant exception, the dentition appears to follow a specific pattern when affected.

Transmitted between mother and child during fetal development, congenital syphilis often creates malformations in the developing dentition. These changes to the teeth have been documented in the New World; however, these cases are, frequently, from historic or proto-historic settings (Jacobi et al., 1992; Hutchinson and Richman, 2006). Ortner (2003:274) poses the question, "Does the bioarchaeological evidence address the issues of where and when the various syndromes developed?" There is evidence from both sides of the Atlantic Ocean of alledged cases of syphilis of consid- in-depth observations of the skeleton, dental traits such as plane-like hypoplastic defect and Fournier's molars are described and compared to previous studies. Additionally, a two-tier system is introduced for describing dental malformations that may suggest either environmental variation in the bacterial assault or in host response. Dental Anthropology 2009;22(3):73-84.

erable antiquity (Baker and Armelagos, 1988; Hillson et al., 1998; Ortner, 2003; Hutchinson and Richman, 2006; Lewis, 2007; Walker et al., 2005), and these fuel debate as to its origins.

The majority of physical evidence in the New World, with regard to congenital syphilis is weighted toward changes to the post-cranial elements, with little description of the teeth (Hutchinson and Richman 2006). Powell and Cook (2005) discuss 16 pre-contact North American specimens with evidence of treponematosis. Included are two regions from the interior of Mexico and four sites along the Pacific coast namely, Alaska, Canada, California, and Baja California, Mexico. The origin for the individual under discussion is the Pacific coastal site of Yugüe, Oaxaca, Mexico.

Here, evidence is presented from a New World case of an individual whose patterns of dental change possibly reflect congenital syphilis. The condition of these archaeological remains restricts this analysis to the teeth and leaves few or no clues elsewhere in the skeletal remains. Dental traits characteristic of this disease are described here and are compared to previous studies.

\section{DENTAL MALFORMATIONS DUE TO CONGENITAL SYPHILIS}

Recent studies on cuspal enamel hypoplasia (CEH) have focused on the disruption of the enamel matrix formation that occurs at the inception of crown development (Ogden et al., 2007). Such enamel defects are

*Correspondence to: Arion T. Mayes, Department of Anthropology, 5500 Campanle Drive, San Diego State University, San Diego, California 92182-6040.

E-mail: amayes@mail.sdsu.edu 


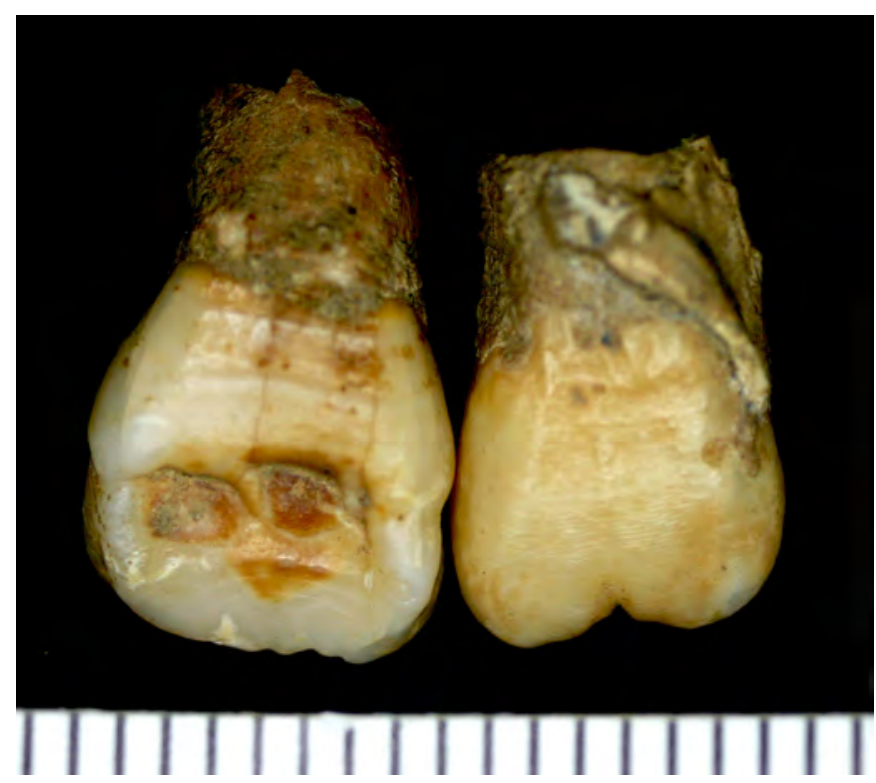

Fig. 1. Labial view of the central maxillary incisors showing patchy hypoplastic defects on the midcrown (right central incisor) and a heart-shaped incisal outline of the crown (left central incisor). The specimen's left maxillary central incisor is on the right of the photograph; the right central is on the left. Scale is in millimeters.

significant because of their timing, as well as their potential association with certain diseases. One such disease is congenital syphilis (Jacobi et al., 1992; Hillson et al., 1998). Congenital syphilis is not always detected at birth, as many of its clinical signs develop later (Mansilla and Pijoan, 1995), or, as in the case of the dentition, are not revealed until emergence (Hillson et al., 1998). Generally, skeletal markers such as bossing of the frontal bone, deformation of the nasal area, and

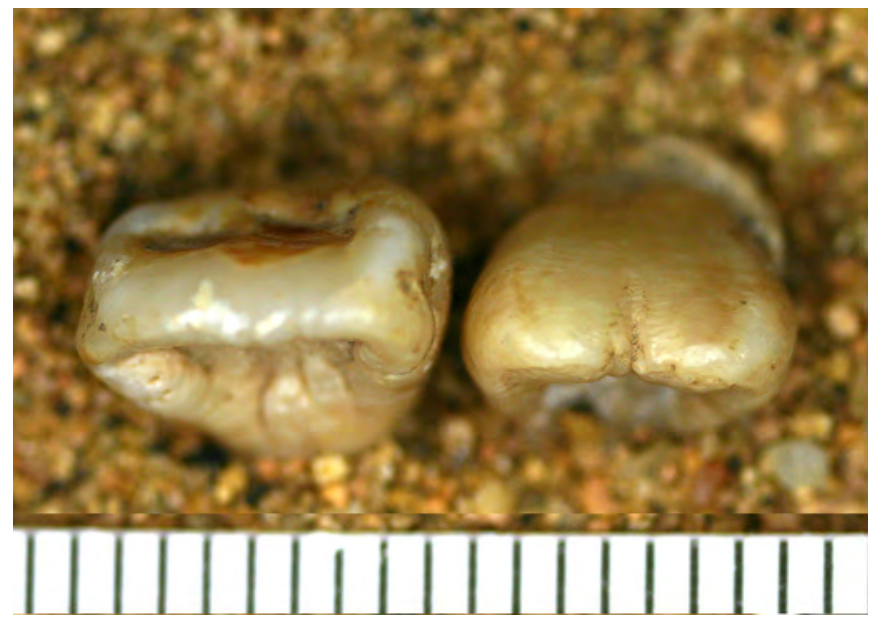

Fig. 3. Occlusal view of the central maxillary incisors showing a patchy hypoplastic defect (labial of right central) and a heart-shaped incisal portion of the crown (left central incisor). Scale in millimeters.

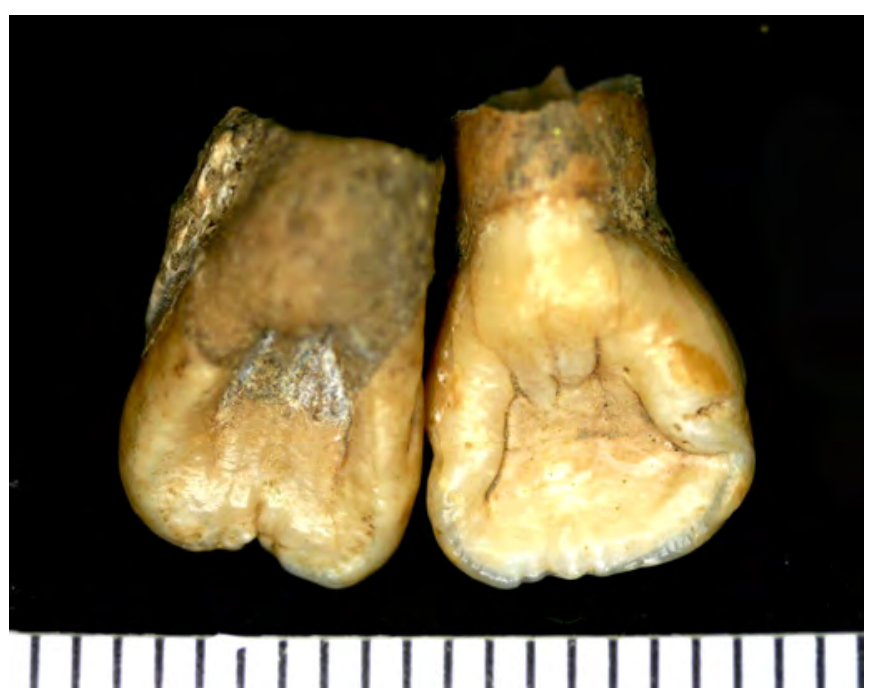

Fig. 2. Lingual view of the central maxillary incisors showing their left-right asymmetry and a heart-shaped incisal portion of the right crown. Scale in millimeters.

inflammation of the tibia, known as sabre shin (Mansilla and Pijoan, 1995; Hillson et al., 1998; Ortner, 2003), are used to identify congenital syphilis in archaeological collections. However, dental defects such as Hutchinson's incisors, extreme linear enamel hypoplastic defects, transverse pitting in the enamel, Moon's molars, and mulberry molars also are considered symptomatic of the disease (Jacobi et al., 1992; Hillson et al., 1998; Ortner, 2003). In archaeological collections, dental stigmata are valuable for diagnosing congenital

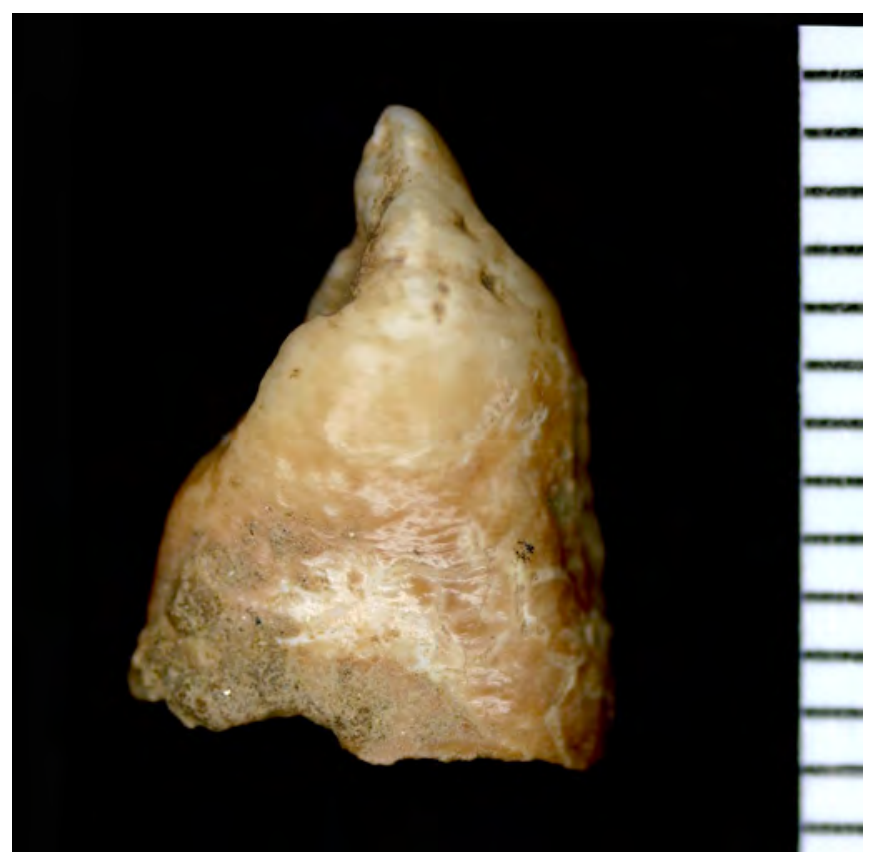

Fig. 4. Lateral view of the left maxillary canine showing the occlusal crown reduction due to extended hypoplastic defect. Scale in millimeters. 


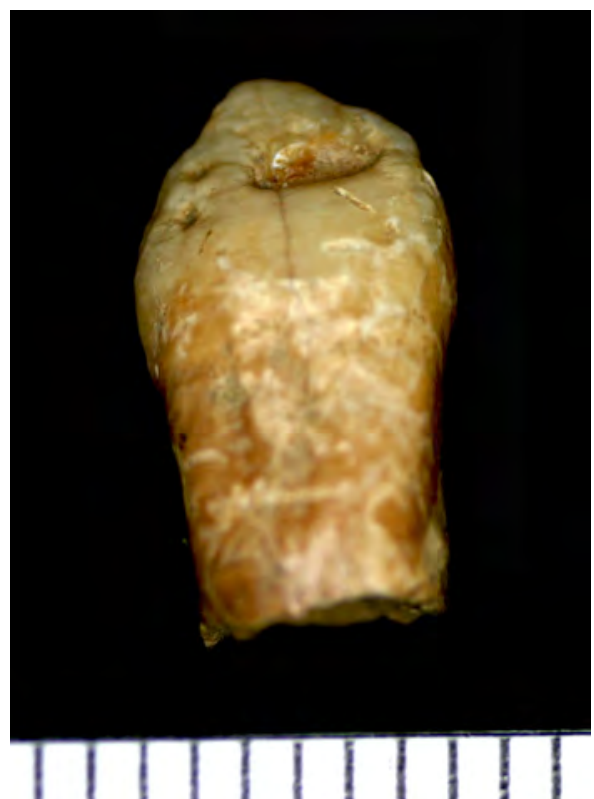

Fig. 5. Labial view of left maxillary canine showing occlusal crown reduction due to hypoplastic defects. Scale in millimeters.

syphilis because enamel does not remodel (as opposed to bone), and because enamel preserves well. A review of the literature, including case studies from historical, ancient, New World, and Old World groups, reveals a two-tier pattern of developmental defects resulting in the described dental stigmata. The first tier, or Level I defect pattern is a result of the genetic timing of tooth development; the second tier, or Level II defects, is an outcome of the environmental expression or, possibly, host response of particular stigmata.

Hillson and colleagues (1998:30) succinctly summarize the four most prominently known changes to the permanent dentition associated with congenital syphilis. Here they are represented by examples in form from the present case study. Note that the Level I conditions follow an identifiable pattern both in cases of known syphilis and archaeological specimens, with

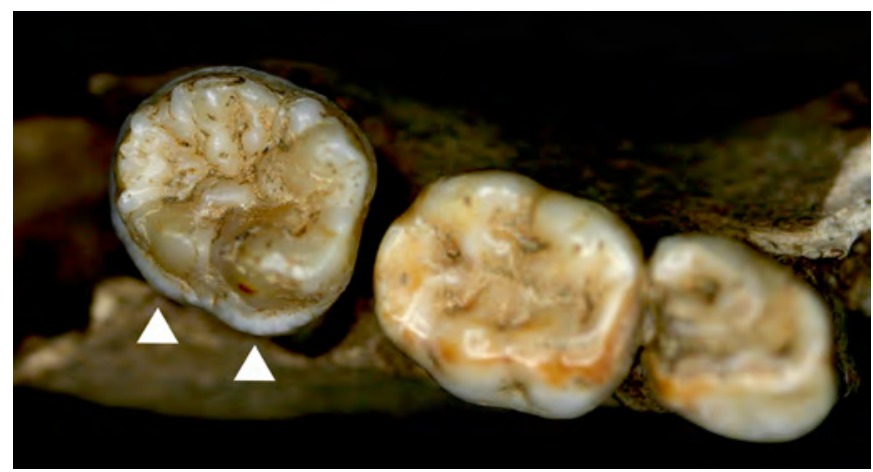

Fig. 7. Occlusal view permanent lower right first molar with reduced irregular cusps and a circumferential plane-like defect (arrows).

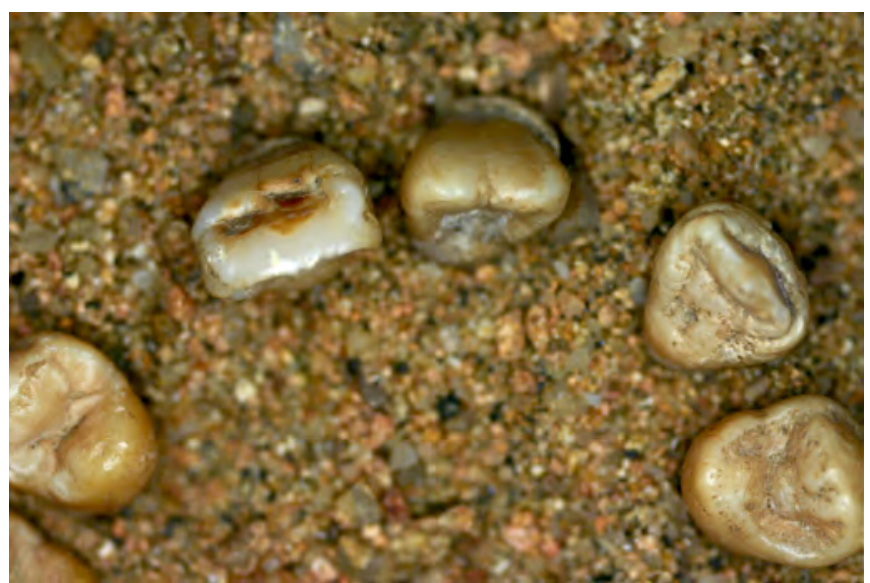

Fig. 6. Occlusal view of the maxillary teeth, showing the change in tooth shape of the central maxillary incisors, and the left maxillary canine. From the left, the teeth are the specimen's right first premolar, right central incisor, left central incisor, left canine, and left first premolar.

slight variation in form for the Level II conditions in reference to the presentation of morphology.

1. "Hutchinson's incisors primarily seen in permanent upper first incisors, but sometimes also in some permanent lower central and lateral incisors (never in permanent upper lateral incisors or canines). Showing a shortened incisal edge, with the mesial

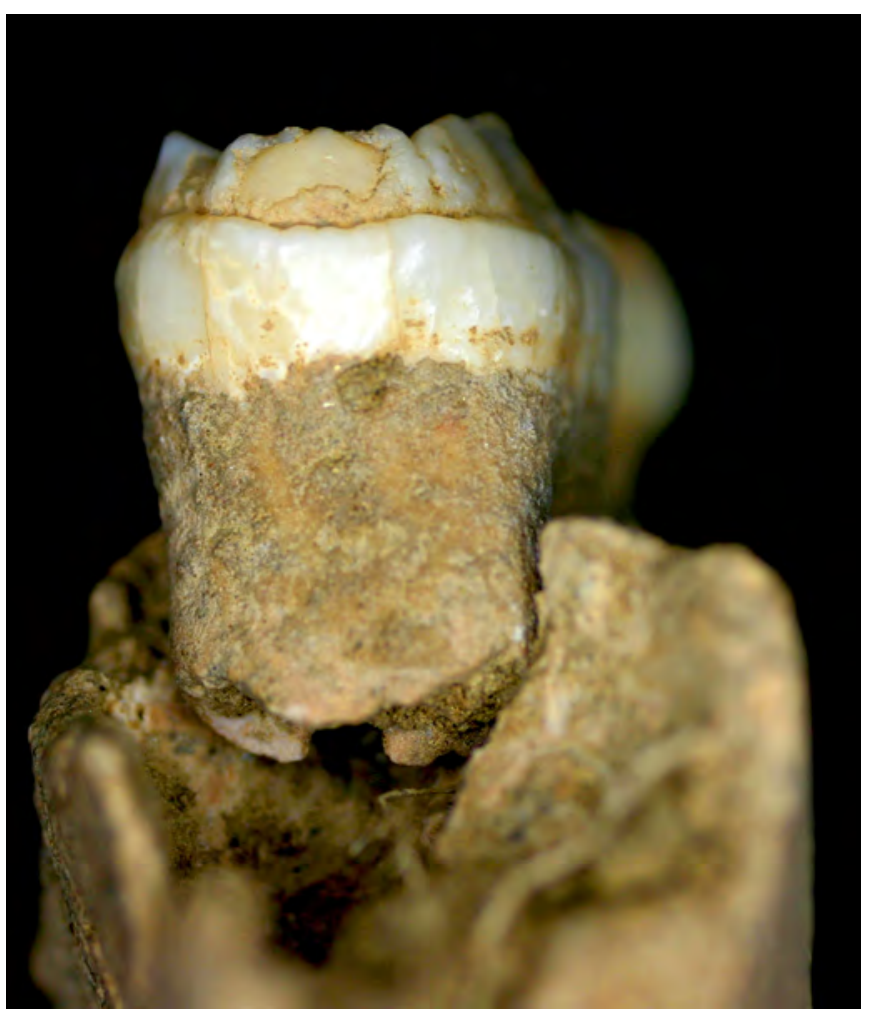

Fig. 8. Distal view of permanent lower right first molar showing circumferential plane-like defect with reduced crown size on coronal portion of the crown. 


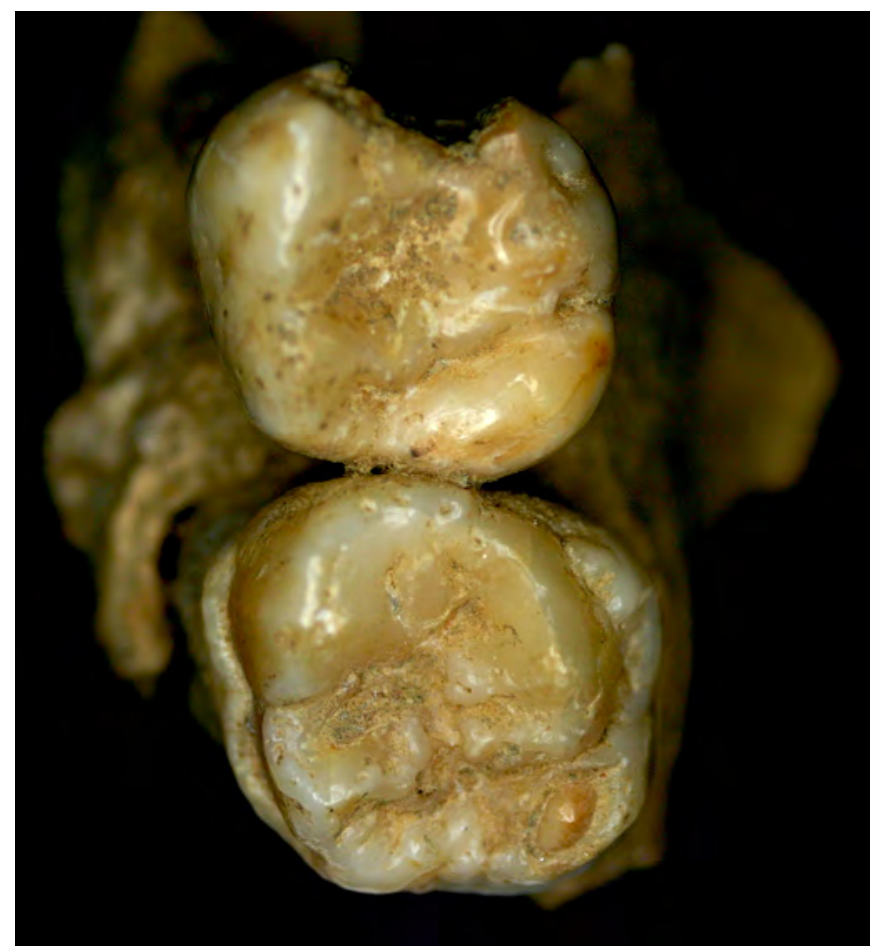

Fig. 9. Occlusal view of permanent right maxillary first molar (bottom) with reduced, irregular cusp and plane-like enamel defect.

and distal crown sides bulging out below it, and marked by a notch of variable shape" (Figs. 1-3).

2. "Permanent upper or lower canines with a sharp groove-like hypoplastic defect around the tip of their single" cusp (Figs. 4-6).

3. "Moon's molars, or bud molars. Only affecting upper and lower permanent first molars. All cusps are abnormally closely spaced, giving a narrow occlusal area relative to the bulge of the crown sides" (Figs. 7-8).

4. "Fournier molars, or more commonly mulberry molars. Also only affecting permanent first molars.

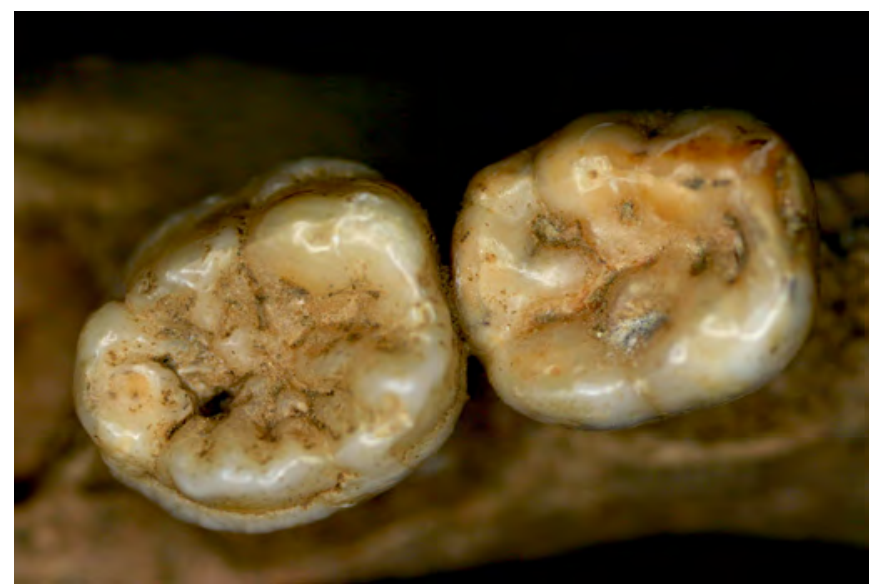

Fig. 11. Occlusal view of permanent left mandibular first molar (left) with circumferential plane-like defect.

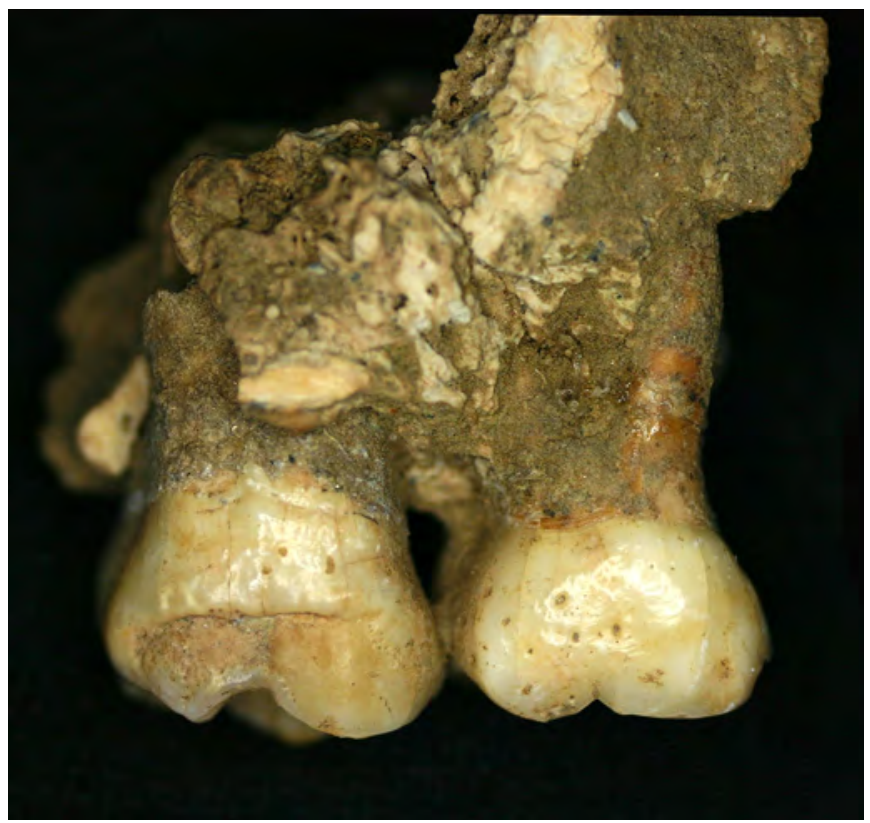

Fig. 10. Interrupted circumferential plane-like defect on the first permanent molar (lingual view).

Showing a marked plane-form hypoplastic defect, cutting sharply into the bases of all the cusps" (Figs. 9-13). The age range for crown defect for the individual presented here is birth to 1.5 years (Goodman and Rose, 1990) to 1.9 years (Reid and Dean, 2006).

\section{CASE STUDY BURIAL 10 - INDIVIDUAL 11}

\section{Archaeological Context}

The presence of these dental stigmata in a juvenile buried at the Pre-columbian site of Yugüe in the Mexican state of Oaxaca are discussed. Occupied from the Middle Formative Period (700 - 400 BCE) until the late Terminal

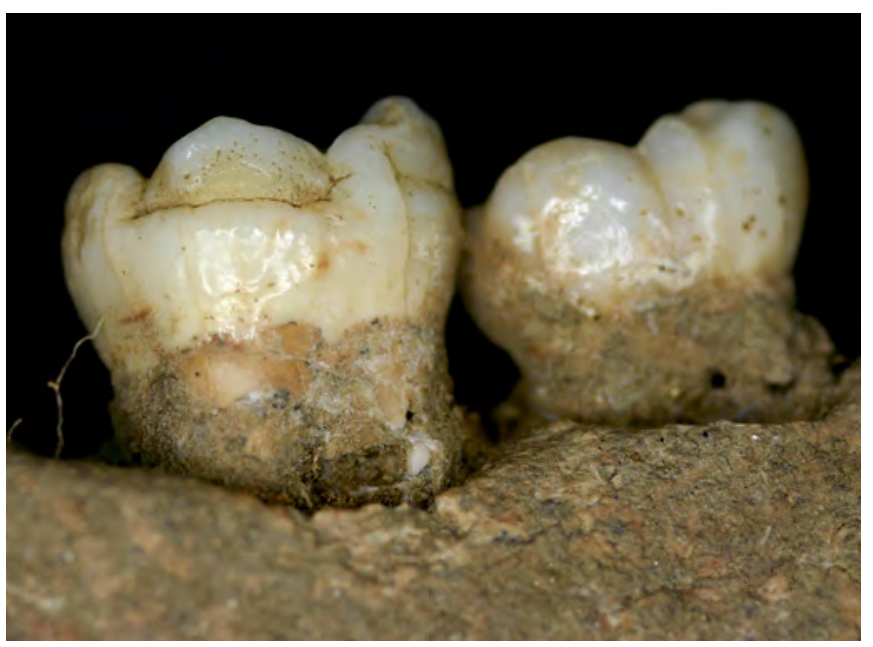

Fig. 12. Interrupted circumferential plane-like defect on the first permanent molar (buccal view; mesial is to the right of the photograph). 
Formative Period (CE 100 - 250), Yugüe is a 9.75 hectare site located on the floodplain of the lower Río Verde Valley on Oaxaca's western Pacific coast. The site was reoccupied in the Late Post-classic Period (CE 1200 - 1522) and persists as a small hamlet today. Historic and modern construction at the site has had a detrimental effect on buried human remains from the site, as discussed below. The core of Formative Period Yugüe was a $10 \mathrm{~m}$ high monumental earthen platform, first constructed around $150 \mathrm{BCE}$, that supported domestic and ceremonial architecture (Barber, 2005; Joyce, 1999). The summit of the platform was used for community ceremonial practices, including temple construction, burial, caching, and feasting (Barber, 2005). Today, a modern chapel sits atop the platform.

Burial 10 Individual 11 (B10-I11), the focus of this report, was part of a temporally and spatially distinct cemetery dating to the late Terminal Formative (Fig. 14). The cemetery contained at least 44 individuals densely-packed into an area of less than $7 \mathrm{~m}^{2}$. Only three individuals were fully articulated; the rest had been disturbed by the internment of later burials, and some may have been secondary burials. B10-I11 is among those that had been disturbed by later burials. The lower half of the individual's skeleton was either removed or displaced by the later internment of at least two individuals. Individuals' ages within the cemetery ranged from neonate to elderly adult, with both males and females represented. In general, adults were buried in an extended position, placed on their right sides, with their heads to the west. Juveniles were placed perpendicular to the adults, lying on their left sides, with their heads to the south. There were some exceptions to this pattern, particularly among individuals who had been severely disturbed by subsequent internments (Mayes and Barber, 2008). The burial fill contained a number of offerings, particularly miniature ceramic vessels and potsherds, most of which could not be directly associated with a particular individual. In a few cases, associated artifacts did indicate that certain individuals were of higher social status than others in the cemetery (Barber, 2005; Mayes and Barber 2008). B10-I11 is one such case, as the individual was buried holding a long strand of green and white stone beads in the right hand. The presence of this socially valuable item has led investigators to suggest that B10-I11 was of high status (Barber, 2005).

\section{Burial Description}

An inventory of remains revealed that the vault and lateral portions of the skull are present. However, the face is crushed with elements identified only as being bone, not allowing for any description of morphology or identification of pathological changes. The frontal, parietal, occipital, temporal, and zygomatic bones are present, with the left sides in fairly good condition, and the right sides crushed and fragmented. There is a partial left portion of the sphenoid, but with the right side missing. Both the maxillae are fragmented, and the nasal and palatine bones are absent. The mandible is present but fragmentary. The lower limbs are missing, but the upper body is represented by the fragmented remains of the distal left humerus, a partial diaphysis and distal epiphysis of the right humerus, a damaged left radius, a portion of the right radial diaphysis, a damaged left ulna, and a portion of the diaphysis of the right ulna. Radiographic analysis was unavailable.

The portion of the skeleton in greatest abundance, and with the best preservation, is the dentition. Both permanent and deciduous teeth are present (Tables 1 and 2).

The taphonomy is substantial and underscores the paucity of information concerning certain skeletal elements that are present, with destruction to several surfaces in some cases, and the adherence of bone fragments and soil on others. This pattern is found in all available elements, including the roots and crowns of teeth. The skull has postmortem plastic distortion, with a slow crushing effect having taken place over the millennia. The practice of burying individuals on their sides resulted in severe damage to crania and innominates in this skeletal series. In B10-I11, the result is identifiable vault and lateral bones, with a complete loss of identifiable elements in the face, particularly around the nasal aperture. In addition, high clay and sand content caused the burial fill to behave almost like cement, with

TABLE 1. Inventory of deciduous dentition by root and crown development ${ }^{1}$

\begin{tabular}{|c|c|c|c|c|c|}
\hline Arcade & $\mathrm{dm} 2$ & $\mathrm{dm} 1$ & $\mathrm{dc}$ & di2 & di1 \\
\hline \multicolumn{6}{|c|}{ Right Side } \\
\hline Upper & PUN & PUN & PB & PUN & Ac \\
\hline Lower & PUN & Ac & PUN & Ac & PUN \\
\hline \multicolumn{6}{|c|}{ Left Side } \\
\hline Upper & PUN & PUN & PUN & PUN & Ac \\
\hline Lower & PUN & & Ac & PUN & PUN \\
\hline
\end{tabular}

${ }^{1}$ PUN stands for present but unobservable; PB stands for present but broken; Ac stands for apex complete. 


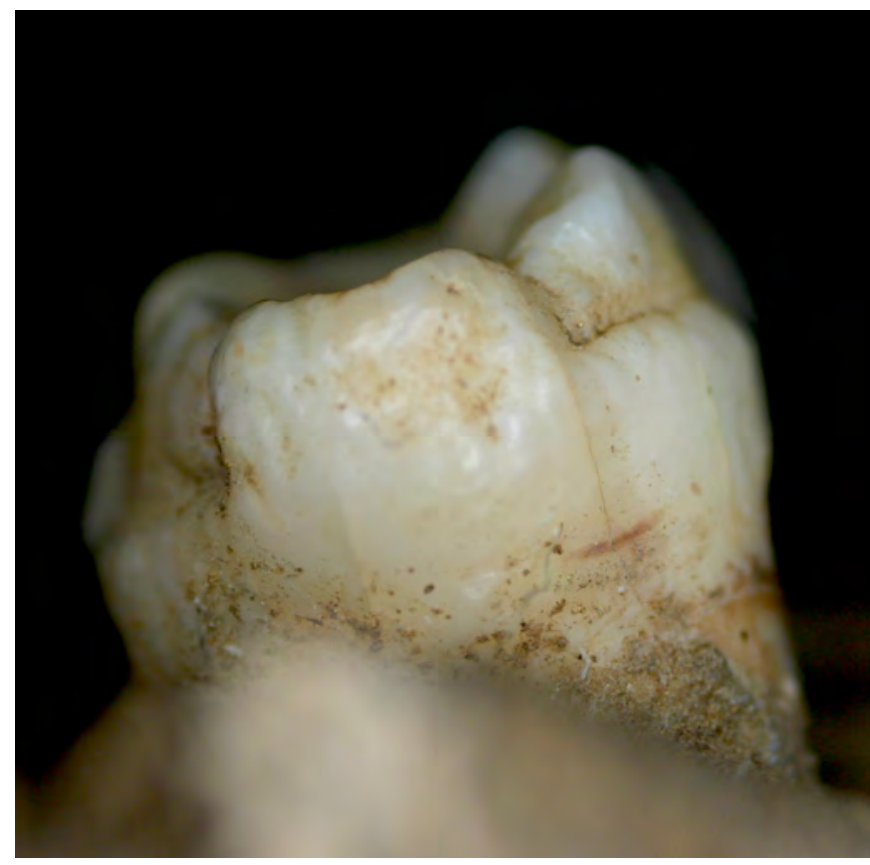

Fig. 13. Distal view, showing the interrupted circumferential plane-like defect on the permanent left maxillary first molar.

a thick crust adhering to the surface of many bones, obliterating any surface changes, and adding to further deterioration of small bones. The material with the best preservation in this collection is the teeth, having gained some protection within the mandible. The taphonomic damage did facilitate determination of the specimen's age: the fragmentary condition of the alveolar bone and loose teeth allowed for the observation of crown and root development of erupting and un-erupted dentition (Figs. 15-18). This was useful given that radiographic analysis of the skeleton was not possible.

Burial 10 Individual 11 represents the remains of a child, age 5-6 years at the time of death, with severe physiological stress markings on his or her dentition. Many of the pathological changes in the teeth mirror those observed in documented cases of congenital syphilis (Figs. 1-13).

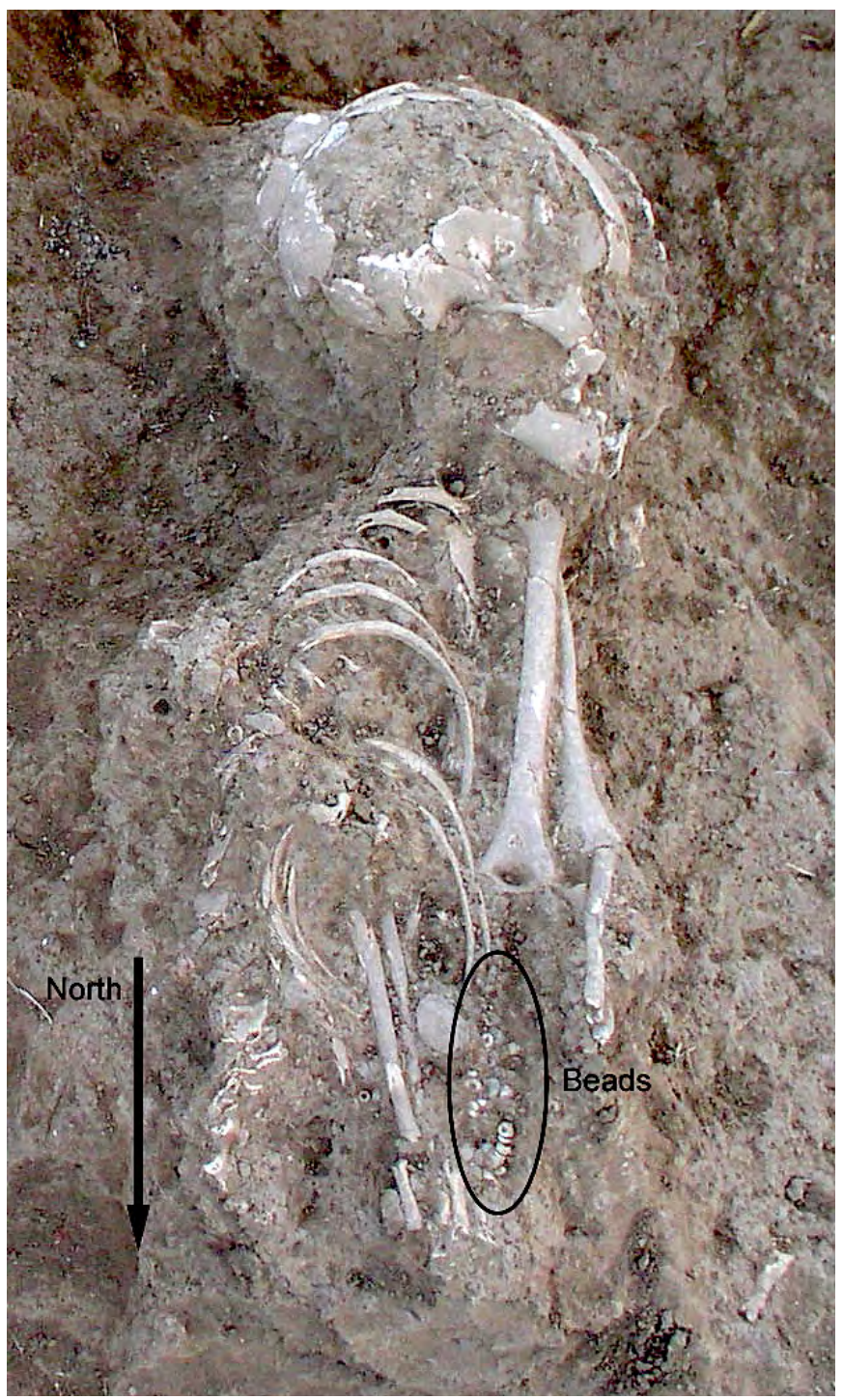

Fig. 14. View of the postmortem breakage that enabled observation of the unerupted dentition for use in dental aging of the specimen. The body was positioned on its left side. This seems to be an extended burial, but the remains of the pelvis and legs are lost.

TABLE 2. Inventory of permanent dentition by root and crown development*

\begin{tabular}{|c|c|c|c|c|c|c|c|c|}
\hline Arcade & M3 & M2 & M1 & P2 & P1 & $\mathrm{C}$ & $\mathrm{I} 2$ & I1 \\
\hline $\begin{array}{l}\text { Upper } \\
\text { Lower }\end{array}$ & & & $\begin{array}{l}\mathrm{R} 1 / 2 \\
\mathrm{R} 3.4\end{array}$ & $\begin{array}{c}\text { Right Sic } \\
\text { Crc }\end{array}$ & Crc & Ccr & $\mathrm{R} 1 / 4$ & $\mathrm{R} 1 / 4$ \\
\hline \multicolumn{9}{|c|}{ Left Side } \\
\hline $\begin{array}{l}\text { Upper } \\
\text { Lower }\end{array}$ & Cr3/4 & & $\begin{array}{l}\text { PUN } \\
\text { PUN }\end{array}$ & PUN & Crc & $\mathrm{Ri}$ & PUN & $\begin{array}{l}\text { R1/4 } \\
\text { PUN }\end{array}$ \\
\hline
\end{tabular}

*PUN stands for present but unobservable, Cr3/4 stands for crown $3 / 4$ complete, Crc stands for crown complete, Ri stands for initial root formation, R1/4 root stands for root $1 / 4$ complete. 


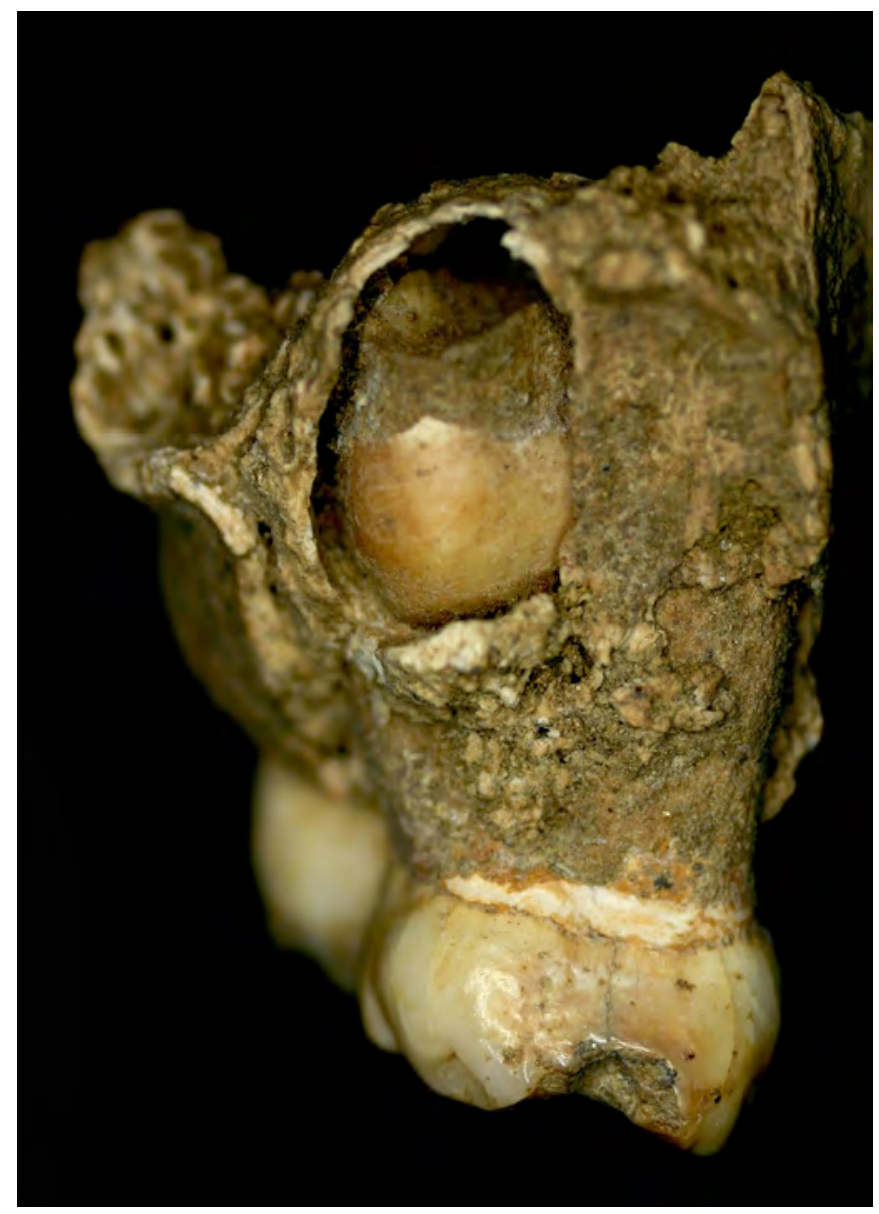

Fig. 15. B10-I11, view of the distal aspect of the maxillary right quadrant. The postmortem breakage of the alveolus exposes the second premolar so it can be used for dental aging.

\section{Deciduous dentition}

The deciduous dentition of this individual is essentially complete, with 19 of the 20 teeth present. There is extensive lytic invasion of the teeth from dental caries. Three out of the seven carious lesions caused decay of over half the tooth surface (URdc, URdi1, ULdm1), and one of these resulted in destruction of the crown (URdc). The other four lesions are not as severe, contributing to less than half of the affected surfaces destroyed (URdm2, URdm1, URdi2, LRdm2). Caries are primarily located on the interproximal surfaces, as well as one on the labial surface. The labial surfaces of the maxillary lateral incisors each have what can be described as wider-thana-pit hypoplastic defect. On these teeth, the enamel appears to have an eroded or patchy appearance, with dark staining around the margins of the defect. Closer examination using magnification revealed abnormal enamel formation, not labial wear or taphonomic change (Fig. 19).

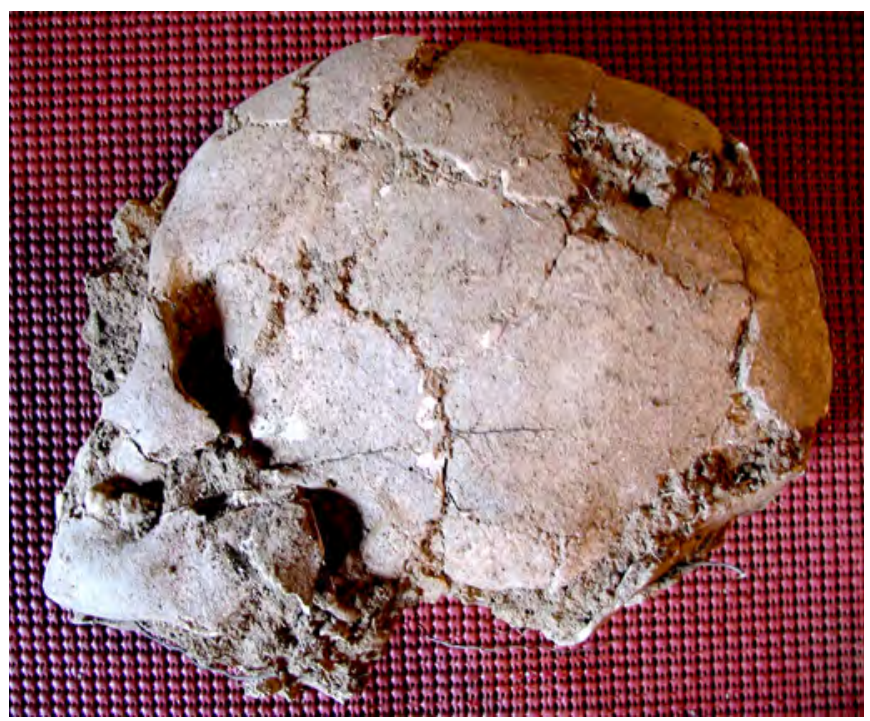

Fig. 16. B10-I11, left lateral view of skull showing taphonomic changes.

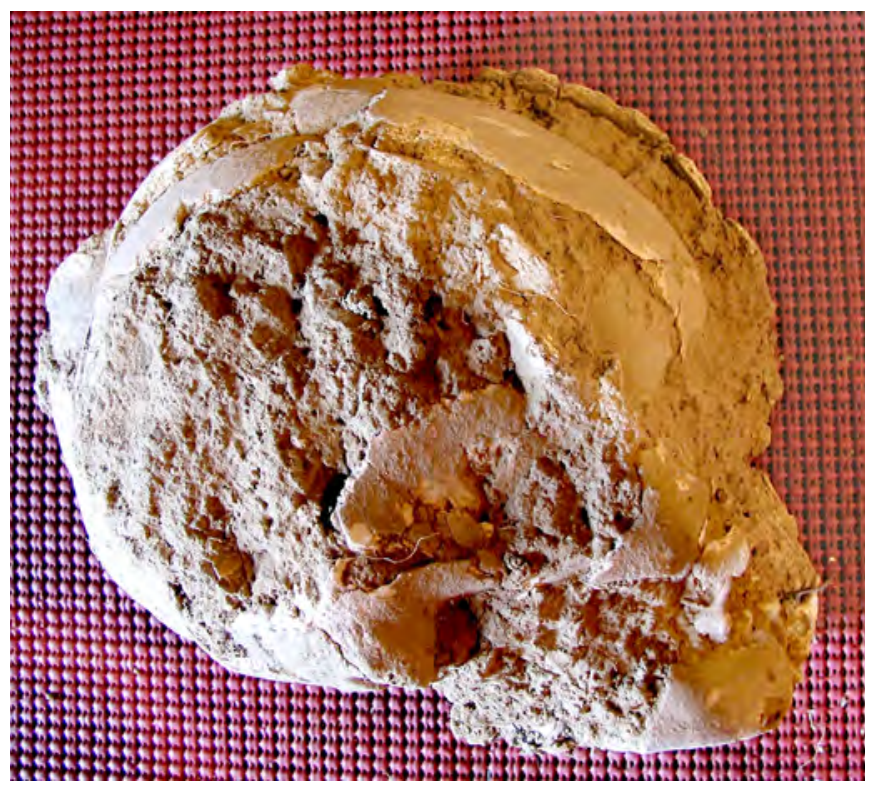

Fig. 17. B10-I11, right lateral view of skull showing taphonomic changes.

\section{Permanent dentition}

The developing permanent dentition exhibits extensive pathology which, unlike the deciduous teeth, is not generalized in nature. There are severe hypoplastic patches, or furrows, present on the labial surfaces of the upper right incisor and both lower central incisors. The defects are approximately $2 \mathrm{~mm}$ by $1 \mathrm{~mm}$ on average (Figs. 1, 20, 21). These defects are irregular. The central maxillary incisor is affected starting from the incisal edge, making the individual around one year old at the time of biological stress (Reid and Dean, 2006), followed by a slight recovery at one point, and then continuing 


\section{A.T. MAYES ET AL.}

until approximately two years old. The defect on the right mandibular central incisor began at around one year of age, with normal enamel formation resuming approximately 6 months later (using Reid and Dean, 2006). The maxillary incisors are symmetrical relevant to being developmentally affected, with the right incisor having two hypoplastic patches and a planelike hypoplastic defect giving a cinched appearance, and the left having an unusual heart-shaped form that is an exaggeration of the normal scalloped shape (see Figs. 1-3). The left maxillary canine has a plane-like hypoplastic defect circumferentially near the occlusal surface, giving the cusp both a reduced and very pointed appearance (occurring between 1.4-2.0 years of age). This fang-like morphology is described in Jacobi et al. (1992) as resulting from cuspal hypoplastic lesions, and often present in cases of congenital syphilis (Fig. 6).

All four permanent first molars are present, and all exhibit a similar defect in form (Figs. 9-13). The occlusal third of the crown is reduced circumferentially from the rest. The base of the crown is wider than coronally, as the occlusal surface is markedly undersize. The difference between this section and the remainder of the crown creates a distinct ridge, which can also be described as a plane-like hypoplastic defect. The occlusal surface appears as a mass of randomly placed globules rather than defined cusps (Figs. 7-8). There is no defect apparent between the plane-like developmental defect and the cemento-enamel junction, indicating that the severe stress occurred very early in life and affected cusp formation from its inception, with relief at around one to one-and-a-half years. In comparison to the permanent second molar, the first molars are reduced in overall size, an additional symptom of the disease (Mansilla and Pijoan, 1995). All of these features are present in descriptions of congenital syphilis (Steinbock, 1976; Hillson et al., 1998).

\section{DISCUSSION}

Given the ongoing debate concerning the origins and antiquity of syphilis, it is important to rule out what the changes in the dentition do not reflect. There are several reasons why the dental defects described here are best interpreted as evidence for congenital syphilis rather than other forms of treponematosis. Congenital yaws, for instance, has been suggested as a cause of syphilislike symptoms (Ortner, 2003). However, dental stigmata described here require the mother to be in the secondary stage of the disease when pregnant, whereas other forms of treponematosis (like yaws) do not produce symptoms until after birth. In terms of other diseases and stresses, children with congenital tuberculosis die shortly after birth (Lewis, 2007), leaving no time for developmental changes to the permanent dentition. A deficiency in vitamin C (scurvy) affects the dentition indirectly, and then only the roots (Lewis, 2007). With regard to non-specific indicators of stress, such as hypoplastic defects, it is clear that a host of diseases can and do cause disruptions and changes in dental formation, but, in these cases, all teeth can be affected. In the case of B10-I11, very specific teeth were malformed at very specific points during development.

As mentioned, a review of the literature on congenital syphilis suggests two levels of patterning in dental defects. Level I defects are genetically tied to the age of development for the involved dentition, and the range of affected teeth within a dental field is restricted to the first incisor, the canine, and the first molar. Level II defects refer to differences in the range of form of the affected teeth, and their variation in environmental expression or host response (which may encompass a differential population response). This range in acquired defects may be particularly important in discerning differences between Old World and New World manifestations of congenital syphilis, or as evidence of multiple syndromes. It should be noted that skeletal manifestations of treponematosis also vary in form and severity. While skeletal changes due to treponematosis have been documented in similar regions of the anatomy or skeletal elements, the degree of involvement differs with each syndrome (Steinbock, 1976). It cannot be ruled out that slight variations in affected dentition may occur as well. For instance, Hutchinson and Richman (2006) discuss permanent first molars from two separate suspected syphilitic New World individuals. "However, neither could be defined as a good example of a Moon's molar" (Hutchinson and Richman, 2006:551). It should be noted, however, that their description of this tooth, and others, fit the Level I rules of affected teeth; the tooth they present (their Fig. 11:555) does have a severe plane-like defect, with a reduction of cusp size from the occlusal tip. The tooth appears to be a slight variation in form of previously described Moon's molars.

The literature varies as to the frequency of dental stigmata in cases of congenital syphilis. The range of 30-45\% (Erdal, 2006; Steinbock 1976; Hillson et al., 1998) can be attributed to discussions on specific characteristics in documented cases and archaeological collections. While these frequencies differ, several points are clear. First, dental stigmata are not exhibited $100 \%$ of the time, even in documented historic cases. Using Putkonen's figures of Hutchinson's incisors being present in $45 \%$ of the cases of congenital syphilis, then it should be equally clear that in $55 \%$ of the cases, they are not. Another facet of the disease is that individuals may not exhibit any of the dental defects, and only show changes in the cranial and post-cranial bones.

When dental defects do exist, depending on when the affected individual died, there is a range of anomalies that do follow a particular pattern. Variation in the morphology of the teeth may be one of the discerning differences between Old World and New World 


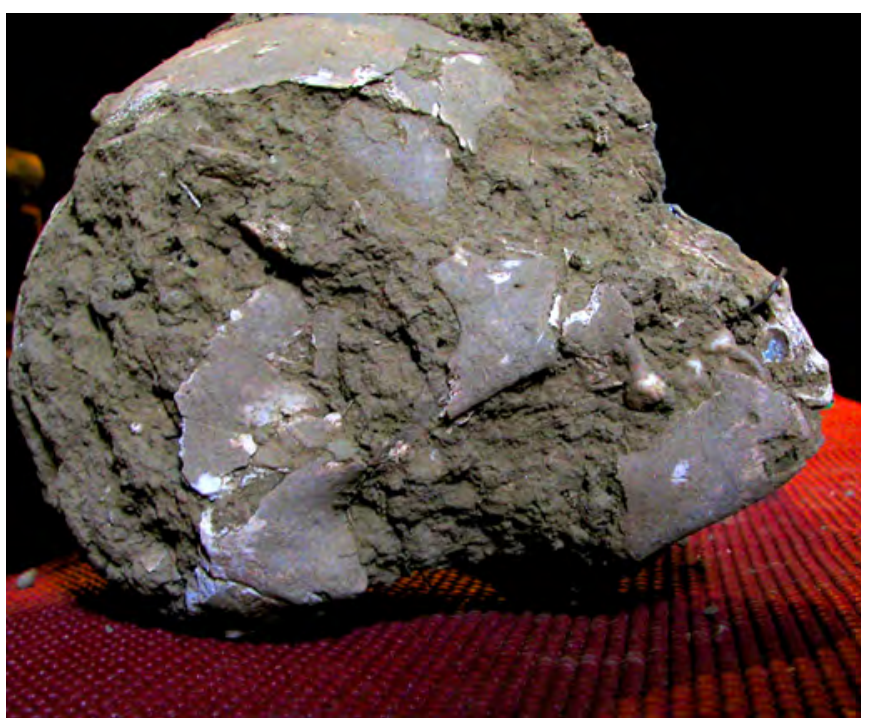

Fig. 18. B10-I11, right lateral view of skull showing taphonomic changes.

manifestations. Therefore, knowing and recognizing variation in symptomology of this disease in antiquity can be valuable. It may also be one of the keys to understanding and identifying various forms of this disease and its dispersion globally.

Hutchinson's incisors affect the permanent teeth, and the feature is primarily seen in the maxillary central and, occasionally, the mandibular incisors. Steinbock notes a wide range of expression in this trait, from the variation described above to "only a depression on the anterior surface of the tooth immediately above the cutting edge, and in some both of these alterations are present" (1976:108). He also notes that it is not always bilateral, and that, in some cases, it may not exist at all. Hutchinson and Richman (2006) describe a child with "malformed enamel sleeves," which they note do not look like Hutchinson's incisors as typically described. However, these two teeth do look very similar to those described by Steinbock (1976). The right central incisor of B10-I11 also has a malformation that is similar in form. In Steinbock's (1976) examples of dental stigmata for congenital syphilis, the lateral maxillary incisors also are affected. This "notch in the incisal margin and rounding of the incisal angle" with a "fissured" labial surface (see Fig. 40 in Steinbock 1976:107) describes, and resembles, the permanent left central maxillary incisor of B10-I11 (Figs. 1-3).

Permanent canines exhibit occlusal hypoplastic defects (Jacobi et al., 1992), and the first permanent molars are also affected by congenital syphilis. A degree of overall consistency is maintained that aids in identification in expected dental stigmata. Descriptive summaries of the defects are also useful in comparing data. Jacobi and colleagues (1992) provide a summary table of descriptions of characteristics attributed to

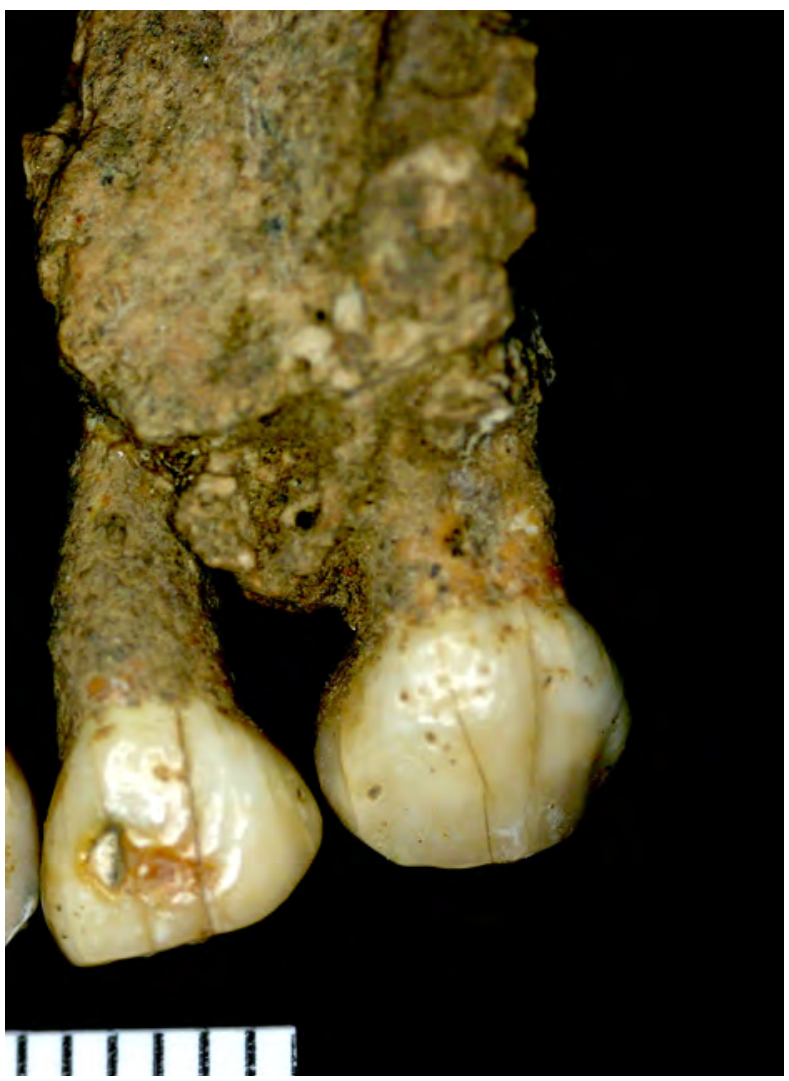

Fig. 19. B10-I11, labial view of the maxillary left lateral incisor with defective enamel in the middle third of the crown. The canine (on the right in the photograph) shows scattered enamel pitting.

congenital syphilis. The main identifying feature of mulberry, or bud, molars is a "marked defect of enamel hypoplasia, running around the base of all cusps. It corresponds to what has been described as a plane-form hypoplastic defect" (Hillson et al., 1998:30). Where the cusps of affected teeth are deformed, having "several small knobs representing atrophic cusps" (Steinbock 1976: 108). In addition to Hutchinson's incisors, both Moon's and mulberry molars are expressions of congenital syphilis.

There are a number of similarities between the teeth from the current study, and that of Hillson and colleagues (1998). Of note are the narrowed occlusal surface, the disorganization of the cusps, and the plane-like hypoplastic defect visible around the circumference. Any combination of these dental defects can be considered expressions of the disease, which is why the degree of certainty in diagnosing congenital syphilis in archaeological specimens can be low, at times. Additionally, the degree to which an individual was affected by the disease, and the observed physical changes present at the time of death, may also affect diagnosis of archaeological specimens. 


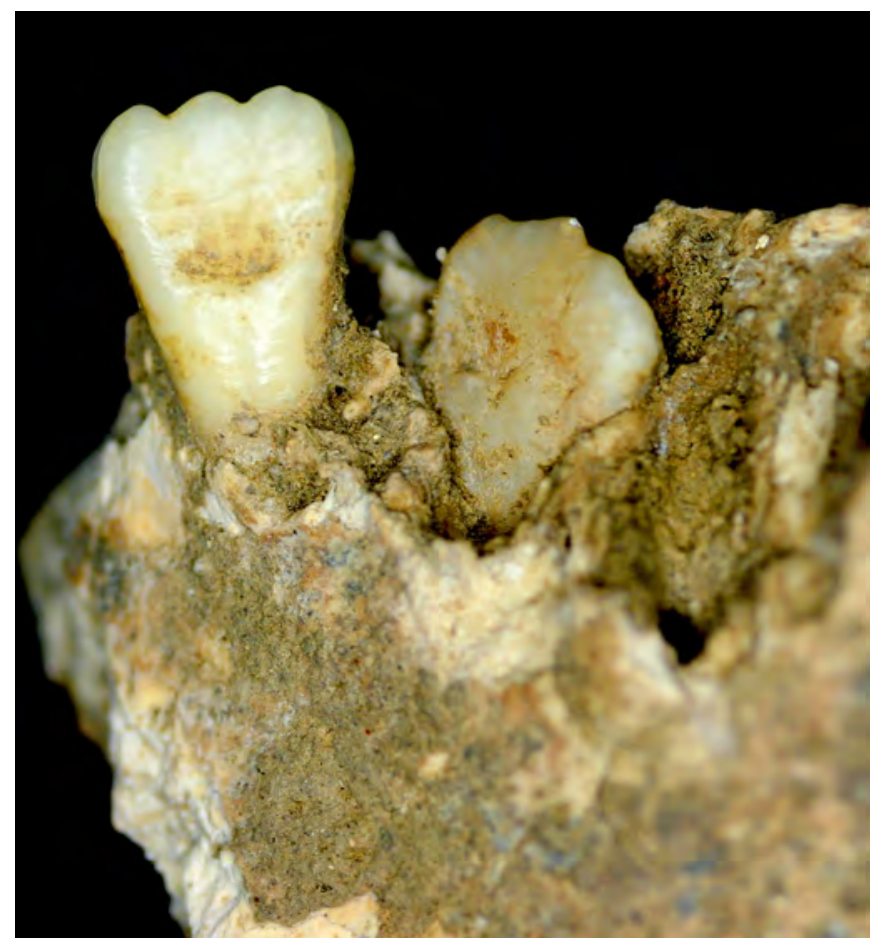

Fig. 20. Deciduous left maxillary lateral incisor with a lingual hypoplastic defect in the middle third of the crown.

Skeletal investigations of pre-contact burials from Gabriola Island, Canada (Pacific Northwest) identified several individuals, adult and sub-adult, with skeletal changes that appear to be due to syphilis. Curtin (2005) describes a disassociated juvenile mandible, the teeth of whom match the current description of syphilitic stigmata, and which parallel case study (B10-I11) presented here, both in terms of the teeth affected and the degree of malformation.

The affected teeth are the two permanent mandibular first molars and the developing right permanent mandibular canine. The molars are severely hypoplastic, with rounded bulbous cusp tips constricted at their base by a deep, irregularly pitted hypoplastic groove that encircles the crown. The cusp tips appear crowded together toward the center of the occlusal surface, which itself features many small, irregular enamel globules, producing the 'mulberry' appearance characteristic of Fournier molars [Curtin, 2005:315].

Additionally, the canines are described as having "circumferential" and "furrow-shaped defects "remarkably similar to one illustrated in Hutchinson's 1887 treatise on syphilis" (Curtin, 2005:315). The described pattern of the canine is a slight variation from Hillson and colleagues' (1998) descriptions, but it mirrors that of B10-I11. Similarly, the authors note that the Gabriola Island individual has a deciduous dentition

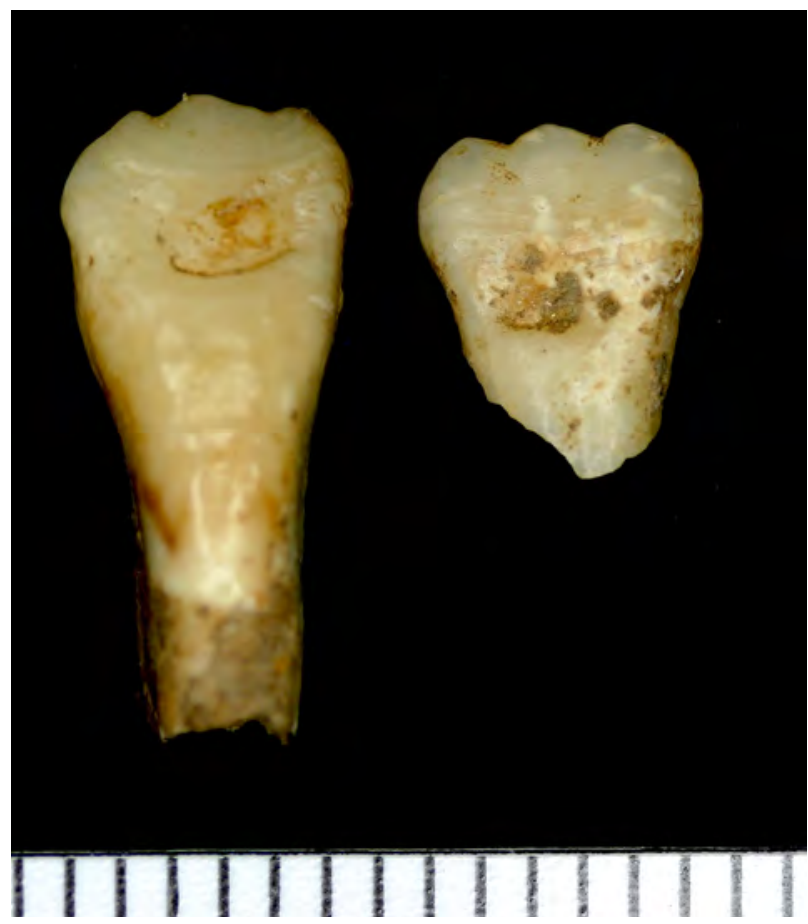

Fig. 21. Permanent mandibular central incisors with furrowed defect in the middle third of the crown; labial view. Distal is to the left of the photograph; scale in millimeters.

with marked hypoplastic defects.

In a skeletal collection from Barbados, Jacobi and colleagues (1992) have described the impact that congenital syphilis had on nineteenth century AfricanAmerican slaves. Three individuals, all adolescents or young adults, had Hutchinson's incisors and Moon's molars. The authors acknowledge that many of the children who died from the disease might not have developed the characteristic dental deformations. They assert that the infant mortality rate due to congenital syphilis was probably quite a bit higher than evidenced by the skeletons themselves. Not all infected infants will acquire the dental stigmata, but most will have changes in some skeletal units. Those who survived to childhood would recover, leaving little evidence of these changes to their long bones during infancy (Steinbock, 1976). This is important, for even if the lower limbs of individual B10-I11 had not been missing, given the age of the individual at death and depending on the severity of the infection, no pathological change may have been evident.

Hillson and colleagues (1998) do not consider the deciduous dentition to be a part of the normal stigmata, but other sources have noted severe developmental disruptions of the milk teeth (Steinbock, 1976; Ortner, 2003; Curtin, 2005; Hutchinson and Richman, 2006). Defects on the deciduous dentition, while not normally considered part of the suite of changes, certainly speak 
to issues with the mother's health during fetal development. Given that congenital syphilis is contracted transplacentally (Lewis, 2007), it is expected that other negative effects on the growing fetus can be documented, so the hypoplastic "patch" identified on the central maxillary deciduous incisor of B10-I11, and additional hypoplastic pitting, are not surprising.

\section{CONCLUSION}

Differential diagnosis of congenital syphilis from skeletal remains should consider all bony and dental manifestations. The postmortem damage to this individual is considerable, with the face splintered, the skull crushed, and the lower extremities absent. Preservation and taphonomy prevented the assessment of the skeletal markers of congenital syphilis in this case. However, the pattern of dental defects that developed is significant and is consistent with previously described changes due to congenital syphilis.

Not every manifestation of treponematosis is completely understood. It is for this reason that all possible cases should be introduced, particularly when what is observed follows a generally recognizable pattern, though with slight morphological variation. Such variations are already documented in the literature (Hillson et al. 1998), meaning that case studies, even from unexpected locales, cannot be ignored. Possibly, expression of some malformations varies by population (genetic and physiological) and/or the environmental framework, but which teeth are affected by this disease process, does not vary. If there are evolutionary differences in form for this disease based on geographic location, or on differing bacteria, they do not appear to affect the Level I rules of dental field pattern. There are, nonetheless, certain variations of Level II-expression of malformations. A better understanding of these differences and their range of expression may aid in identifying New World and Old World syndromes in antiquity. The data presented here is suggestive of a congenital form of treponematosis in the New World, possibly congenital syphilis.

\section{ACKNOWLEDGMENTS}

We would like to thank the Instituto Nacional de Antroplogía e Historia for sanctioning the skeletal analysis on which this paper is based. We are particularly indebted to the President and members of the Consejo de Arqueología, the directors of the Centro INAH-Oaxaca, including Eduardo López Calzada, and Doctor Sergio López Alonso. We would also like to thank Angela Berg Collins for photographic archiving the dentition presented here, and field assistant José Aguilar. Funding for the osteological field research was provided by grants from the College of Arts and Letters, and a Research, Scholarship, and Creative Activity Grant (RSCA), San Diego State University.

\section{LITERATURE CITED}

Baker, BJ, Dupras TL, Tocheri MW. 2005. The osteology of infants and children. College Station, Texas A\&M Press.

Barber SB. 2005. Heterogeneity, identity, and complexity: negotiating status and authority in terminal formative coastal Oaxaca. Ph.D. dissertation, University of Colorado, Boulder.

Centurion-Lara A, Castro C, Castillo R, Shaffer JM, Van Voorhis WC, Lukehart SA. 1998. The flanking region sequences of the $15-\mathrm{kDa}$ lipoprotein gene differentiate pathogenic treponemes. J Infect Dis 177:1036-1040

Cook DC, Buikstra JE. 1979. Health and differential survival in prehistoric populations: prenatal dental defects. Am J Phys Anthropol 51:649-664.

Curtin AJ. 2005. Prehistoric treponematosis in the Pacific Northwest: a review of the skeletal evidence. In: Powell ML. and Cook DC, editors. The myth of syphilis: the natural history of treponematosis in North America. Gainesville: University of Florida Press. p 306-330.

Duray SM. 1990. Deciduous enamel defects and caries susceptibility in a prehistoric Ohio population. Am J Phys Anthropol 81:27-34.

Erdal YS. 2006. A Pre-Columbian case of congenital syphilis from Anatolia (Nicaea, 13th Century AD). Int J Osteoarch 16:16-33.

Goodman AH, Armelagos GJ. 1985. Factors affecting the distribution of enamel hypoplasias within the human permanent dentition. Am J Phys Anthropol 68:479-493.

Giuliani M, Latini A, Palamara G, Maini A, Di Carlo A. 2005. Correspondence: The clinical appearance of pinta mimics secondary syphilis: another trap of treponematosis? Clin Infect Dis 40:1548-1549.

Hillson S, Bond S. 1997. Relationship of enamel hypoplasia to the pattern of tooth crown growth: a discussion. Am J Phys Anthropol 104:89-104.

Hillson S, Grigson C, Bond S. 1998. Dental defects of congenital syphilis. Am J Phys Anthropol 107:25-40.

Hutchinson DL, Richman R. 2006. Regional, social, and evolutionary perspectives on treponemal infection in the Southeastern United States. Am J Phys Anthropol 129:544-548.

Jacobi KP, Cook DC, Corruccini RS, Handler JS. 1992. Congenital syphilis in the past: slaves at Newton Plantation, Barbados, West Indies. Am J Phys Anthropol 89:145-158.

Kolman CJ, Centurion-Lara A, Lukehart SA, Owsley DW, Tuross N. Identification of Treponema pallidum subspecies pallidum in a 200 year-old skeletal specimen. J Infect Dis 180: 2060-2063.

Larsen CS. 1997. Bioarchaeology: interpreting behavior from the human skeleton. Cambridge: Cambridge University Press. 
Lewis M.E. 2007. The bioarchaeology of children. Cambridge: Cambridge University Press.

Mansilla J, Pijoan CM. 1995. Brief communication: A case of congenital syphilis during the Colonial Period in Mexico City. Am J Phys Anthropol 97:187-195.

Mansilla J, Pijoan CM. 2005. Treponematosis in ancient Mexico. In: Powell ML and Cook DC, editors. The myth of syphilis: the natural history of treponematosis in North America. Gainesville: University of Florida Press. p 368-385.

Mayes AT, Barber SB 2008. Osteobiography of a high status burial from the lower Río Verde Valley of Oaxaca, Mexico. Int J Osteoarch 18:573-588.

Ogden AR, Pinhasi R, White WJ. 2007. Gross enamel hypoplasia in molars from Subadults in a 16th-18th Century London graveyard. Am J Phys Anthropol 133:957-966.

Ortner DJ. 2003. Identification of pathological conditions in human skeletal remains, 2nd ed. Amsterdam: Academic Press.

Powell ML, Cook DC. 2005. The myth of syphilis: the natural history of treponematosis in North America. In: Powell ML. and Cook DC, editors. The myth of syphilis: the natural history of treponematosis in North America. Gainesville: University of Florida Press. p 1-8.

Reid DJ. 2006. Variation in modern human enamel formation times. Hum Evol 50:329-346.

Rothschild BM. 2005. History of syphilis. Clin Infect Dis 40:1454-1463.

Santos RV, Coimbra CEA. 1999. Hardships of contact: enamel hypoplasias in Tupí-Mondé Amerindians from the Brazilian Amazonia. Am J Phys Anthropol 109:111-127.

Steinbock RT. 1976. Paleopathological diagnosis and interpretation: bone diseases in ancient human populations.Springfield, Illinois: Charles C. Thomas. 